\title{
After decision-making: the operationalization of norms in International Relations
}

\author{
HENDRIK HUELSS \\ School of Politics and International Relations, University of Kent, Canterbury, UK \\ E-mail: h.c.huelss@kent.ac.uk
}

\begin{abstract}
Research on norms in International Relations (IR) includes various concepts related to how norms influence actions. These approaches focus on the decision-making process, and largely neglect the operationalization of norms. This omission leads to an analytical gap: a lack of attention to how the substance of abstract norms is transformed and constructed in the operationalization process. This article draws on the Foucauldian theme of governmentality to introduce a novel perspective on operationalizing norms. It focusses in particular on the role of techniques as understudied parts inherent to the reflexive processes of operationalization and meaning production. The article thereby contests the prevalence of fundamental norms in conventional IR theory. It demonstrates, instead, that global governance techniques do not simply translate rationalities into practice, but construct their very own normativities. These theoretical reflections are illustrated by analysing the operationalization of norms through indicators in the case of the European Union's human rights policy.
\end{abstract}

Keywords: norms; operationalization; governmentality; logic of action; EU; human rights

At its most basic, International Relations (IR) research concerned with analysing actions often investigates 'what is perhaps the most interesting and challenging puzzle in international relations theory - disentangling the relationship between strategic actors and social/normative influences' (Hurd 2008, 310). Over the last two decades, research on norms in IR has developed several approaches to understanding how, why, and which norms influence human actions. The two major interrelated research strains of norms research, which consider the emergence and impact of norms, respectively, have provided various conceptualizations to explain how norms matter, such as 'socialization' (Risse and Sikkink 1999; Zürn and Checkel 2005), 'norm diffusion' (Acharya 2004), 'learning and persuasion' (Checkel 2001), or 'norm entrepreneurs' (Sunstein 1996; Finnemore and 
Sikkink 1998). Furthermore, different logics of action, most prominently the logic of appropriateness (March and Olsen 1989), the logic of arguing (Risse 2000), the principle of contestedness (Wiener 2007a; Wiener 2014), and the logic of practicality (Pouliot 2008), discuss whether and how norms inform actions from diverging epistemological and ontological standpoints. However, existing research only examines the questions of why actors follow particular norms and how to understand varying degrees of compliance. In that, studies tend to overlook how norms are implemented - particularly the techniques that are used to operationalize norms in practice.

This article considers the question what kind of role the operationalization of norms play and how normative substance is constructed in the process of operationalization. This is particularly relevant in settings where the decision about which norms should be followed is separate from the implementation of these norms. The separation of decision-making and implementation is not only fundamental for theoretical approaches, it is also practical reality in all forms of complex governing settings. In this regard, various IR studies are based on a sequential and conceptual-logical differentiation between decision-makers and norm-implementers. In this ideal-type understanding, administrative bureaucracies and other implementing agencies are executing clearly defined targets and operationalize fixed norms. However, what kind of norms do implementers follow and how is normative meaning translated into practice?

Norms research has only delivered extensive conceptualizations at the 'front end' of the underlying analytical and chronological dichotomization between decisions and actions. In other words, while we know a lot about the impact mechanisms of norms, abstract norms such as human rights (HR) or conceptions of democracy - which are codified in written documents, reproduced in discourses and expected to shape decisions - are only given substance in making them administratively operational and implementing them 'on the ground'. The divergence and convergence of meaning attributed to such norms has received much attention. However, the analysis of normative content in IR often focusses on international decisionmaking arenas in broad terms, and neglects the possibility that the operationalization of norms could have transformative effects. ${ }^{1}$ While there are different ways how norms are made operational, entailing a vast array of acts, actors and objects, operationalizing norms in the sense of social sciences involves translating 'an abstract theoretical concept into something that can be empirically measured' (Payne and Payne 2004, 142). This process entails developing procedures (such as assessments, evaluations,

${ }^{1}$ The term decision-making level does not imply that decisions are absent at the local (implementation) level. It refers to the dominant logical separation in theoretical terms. 
and monitoring processes) to generate comparable and calculable data and indicators, particularly to gauge the progress in implementation. However, the act of translating norms into operational concepts transforms (or even defines) their substance. These technical processes normally take place at the administrative level rather than at the decision-making level and are more influential than 'the agency role of norm-takers' (Acharya 2004,240 ) in terms of interpretative 'localization'.

Yet, what are the effects of such technical procedures, and what does the operationalization of abstract, universal norms imply in normative-political terms? This article draws on the Foucauldian theme of governmentality to analyse techniques used in the 'daily business' of global governance. Norms can be operationalized through constitutional documents and evaluation guidelines, through standardized procedures or informal ways of doing things, and are enacted locally in micro-practices. For example, norms such as gender equality can be made operational by creating quantitative indicators that measure the number of girls enrolled in primary/secondary school or by building a teaching facility for female students in rural parts of sub-Saharan Africa. From this perspective, operationalization refers to the processes and techniques used in the implementation of norms. Specifically, the article focusses on statistical, indicator-based operationalization as an understudied type of operationalization that is key to the role of norms in governance approaches.

Studying governing as governmentality, which refers to a complex arrangement consisting of interacting rationalities and technologies, opens up new possibilities regarding how techniques such as statistical quantification operationalize supposedly pre-defined norms. The underlying feedback loop of norm operationalization, which is at the core of the constitutive role of 'public policy instruments' (Lascoumes and Le Galès 2007) that give substance to various norms, provides a concept to accommodate the normativity of norms that might depart from the initial intentions or objectives of 'normsetters'. The processes examined in this article are based on the assumption that functional-rational tools do not simply serve to execute political objectives: techniques produce normative substance that is basically decoupled from ideational factors that are ontologically prioritized by many approaches studying the role of norms. The focus on techniques hence fills an important gap in the literature. Overall, the article elaborates on how normative substance is constructed in the process of operationalization.

The article empirically illustrates this approach by discussing how the European Union (EU) operationalizes HR. It makes a threefold contribution to the literature. First, it focusses on the discourse of norms as constitutive and constituted to address the theoretical blind spot of norms research regarding how norms are operationalized. Second, it outlines the normative relevance of 
governing techniques. Finally, it emphasizes the importance of considering the operationalization of norms in practice.

The remainder of the article is organized as follows. The first section discusses the propositions of norms research meant to study the rationality of actions and the impact of norms. It reviews influential concepts in IR research on norms, and sets the scene for the viewpoints delivered by studies of governmentality presented in this article. The second section introduces a Foucauldian conceptualization of norms, technologies, and techniques that are central for governmentality. The final section provides empirical examples of the theoretical discussion by studying how the EU's HR policy operationalizes fundamental norms.

\section{Setting the scene: norms, actions, and operationalization}

As Finnemore and Sikkink noted in their influential contribution to the 'constructivist turn', '[n]orms and normative issues have been central to the study of politics for at least two millennia' (1998, 889). But what role do norms play in the practice of government? Considering this question in the IR context conventionally starts by defining what norms are before discussing how they shape decisions. One of the most widely used definitions posits that norms are "collective expectations for proper behaviour for a given identity' (Jepperson, Wendt, and Katzenstein 1996, 54). While this understanding is not universally shared, the crucial question is whether the definition of norms can be separated from their function or role. Theories of action address this point: the 'logic of appropriateness' (March and Olsen 1989) as an important norm-following approach conceptualizes 'rules of appropriateness' as 'embodied in the foundational norms of contemporary democracies' (March and Olsen 2004, 6). Challenging this view and 'the stable quality of norms or the facticity dimension as the make or break point for the power of norms, establishing whether norms are followed by a group of actors who consider them as either appropriate or legitimate' (Wiener 2007b, 54), the logic of arguing (see Risse 2000) and the principle of contestedness (Wiener 2007b, 2008) ontologically prioritize the communicative-discursive dimension. The logic of arguing suggests that actors in international negotiations are not always certain which norm should be appropriately followed, and they are involved in deliberations about the contextual relevance of specific norms. This points to the tension between the facticity of norms as existing standards and their validity across different contexts deriving of Habermasian theory. The basic assumption is that legal structures are constitutive of abstract and positive rights, which makes laws the subject of interpretation according to factual historical conditions. With this in mind, Wiener $(2007 \mathrm{a}, 8)$ argues that the meaning of 
'fundamental norms', such as HR, democracy, sovereignty, and the rule of law, which are the type of political norms most IR studies refer to, are contested by default. Therefore she introduces a typology of norms that differentiates 'fundamental norms' from 'organizing principles' such as accountability, transparency, and flexibility and from 'standardized procedures' such as qualified majority voting, unanimous decisions, and proportional representation (Wiener 2007a, 8).

Acknowledging the 'dual quality of norms' (Wiener 2007b) as constitutive and constituted in the tradition of structuration theory in IR (Wendt 1987) has contributed to refining perspectives on norms in IR. The categorization and ultimate definition of norms intensify an analytical fragmentation that prioritizes the construction and stabilization of meaning at specific points in time though. Furthermore, the question is not only whether and what kinds of effects different types of norms have, but also how these norms relate to each other. Are fundamental norms to be conceptualized separately from organizing principles and standardized procedures when studying their emergence and effect? How does the operational implementation of norms play into this?

These highly influential concepts of norms in IR discussed thus far assume a more or less stable normative structure. The deliberation or contestation, and reinterpretation of meaning presupposes a reflective process inherent to actors who basically consider what norms mean to them. Moreover, norms research privileges a particular concept of disagreement which is based on the assumption that actors follow different norms and seek to promote their own understanding of normative meaning. While this is certainly the case to some extent, it is largely unconsidered that basic techniques to implement norms are rarely subject to reflective deliberation, contested by default, or external to the supposed processes of social norm construction.

In a similar vein, the Bourdieuan-inspired logic of practicality criticizes popular approaches for their exclusive focus on reflective, deliberative processes. Proponents of this logic argue that actions are not always the outcome of profound reflections on the appropriateness and meaning of norms; instead, 'practical' or 'background knowledge' (Pouliot 2008, 258) informs common sense ways of proceeding. This focus on how ideas and practices relate is an important contribution of the logic of practicality: theoretical perspectives emphasizing the co-constitution of structure and agency, inherent to the previously discussed social constructivist approaches, and logics of action, fail in this regard. Thus, actors follow a sequential logic in which knowledge constitutes the rationale for actions.

However, if we understand 'practical knowledge as unreflexive and inarticulate through and through' (Pouliot 2008, 265), how does knowledge come into play in the operationalization phase, which is associated 
with much longer time frames? Operationalizing political decisions, such as those taken by complex, multi-layer organizations like the EU, is different from the intuitive reactions of a football goalkeeper attempting to save a penalty, to refer to a common example of Bourdieuan practice theory. ${ }^{2}$ The posited 'ontological priority of the logic of practicality' (Pouliot 2008, 270) reproduces a central (but widely neglected) problem of action theories and norms research in simply stating that '[p]ractices translate structural background intersubjective knowledge into intentional acts' (Adler and Pouliot 2011, 16).

Recent contributions discussing the merits of actor-network theory (ANT) (Barry 2013; Best and Walters 2013a, 2013b; Nexon and Pouliot 2013; Bueger and Bethke 2014) have reconsidered the question of 'translation' (see Rose and Miller 1992, 184) in the context of IR scholarship. Their main assumption is that ' $[\mathrm{t}]$ ranslation is a process of replication or imitation and differentiation at the same time' (Barry 2013, 415). Broadly, ANT shares an interest with the 'material turn' and the 'new materialism', which is also contextualized in governmentality studies (Lemke 2015; Lundborg and Vaughan-Williams 2015), in 'the materiality of knowledge production' (Best and Walters 2013b, 347) and in the usage of technical devices or machines to translate social reality into comparable and accessible data. While this phenomenon of translation in networks, which entails a common language of indicators and similar constructs harmonizing concepts of global governance, for instance, offers important viewpoints on the transition of knowledge in the micro-practices of administrative-technical operationalization, the actual normative reconstruction remains unconsidered. The intended or unintended transformations and mistakes made when translating meaning across conditions, cultures, and languages is significant (see Apter 2001), but translation works in two directions: for example, the economic situation of a country is assessed and translated into indicators such as GDP growth and inflation rates, while macro-concepts, micro-standards, and political norms also feedback to the initial programme during the operationalization process. This points to the transformative quality of operationalization.

The feedback loop of normative substance emerging here contests the assumption that norms are only constituted and constitutive at the decision-making level. I argue that it is important not simply to reverse the

2 This critique has not gone unnoticed by sociologists working with Bourdieuan concepts: Lahire has, for example, noted how Bourdieu's reflexive, practical logic of action privileges a particular type of social situation: one that necessitates reflexive behaviour at the expense of other types of social situations that require the reflective engagement of actors with longer time frames. However, Bourdieuan-inspired practice theory in IR has not yet accommodated this critique (see Lahire 1998; Bode 2015, 39). 
sequence of decisions followed by actions, but to investigate how techniques are applied as part of programmes that are in turn redefined by the substance produced through techniques. This circuit of normativity is related to two crucial questions: where does the actual substance of norms originate and how does (legal or statistical) normality refer to normativity? The assumption that normative substance is derived from a narrowly defined conception of law in the sense of codified rules is just as unsatisfactory (see Finnemore and Toope 2001, 746-47) as analysing only the ideational-discursive part of decision-making, while neglecting the back end of the action process in terms of operationalization.

In sum, norms research either (1) overemphasizes the importance of deliberations and decision-making in defining norms at the expense of normative substance in practice (logic of appropriateness, logic of arguing, principle of contestedness), or (2) disregards the tension between decision and implementation by classifying norms as diffuse background knowledge and ignoring their technical operationalization (logic of practicality). In contrast to the extensive academic elaboration on the ideational processes of norm socialization, internalization, diffusion, and compliance (e.g. Archibugi 1992; Schimmelfennig 2000; Börzel and Risse 2012; Börzel and Solingen 2014), my perspective on the operationalization of norms assumes that norms are not fixed and simply put into practice; acts of governing are always based on certain techniques that have a constitutive effect. In other words, the decisive question is what happens to norms after decisions have been made, which requires thinking beyond the ideal-type decision-making arena that is conceptualized as prior to the executive, administrative dimensions. In that, I argue that the meaning of norms is defined and constructed in the operationalization process. As aforementioned, there are different types of operationalization - the measurement of fundamental rights through indicators, the judicial interpretation of legal norms, or the fusion of global HR and local norms in fieldwork contexts that creates novel standards of appropriateness. While these processes are complex and require extensive in-depth analyses, it is apparent how considering the operationalization of norms contributes to an understanding of their meaning and function.

The following section on the study of governmentality offers novel viewpoints on the construction of norms and on how indicators as central element of one type of operationalization are important for the role of norms in the practice of global governing.

\section{Governmentality and the role of norms}

In his lecture series on governmentality, which is defined as 'the ensemble formed by institutions, procedures, analyses and reflections, calculations, 
and tactics that allow the exercise of this very specific, albeit very complex, power that has the population as its target, political economy as its major form of knowledge, and apparatuses of security as its essential technical instrument' (Foucault 2007, 108); Foucault describes three mechanisms of conduct that emerge in the historical development of government and are important for understanding the role of norms: the legal prohibition, the disciplinary prescription, and the normalization by security apparatuses. Foucault considers the differences between the effects of the law, the discipline, and security, respectively, from the viewpoint of normalization as an ill-defined and vague concept that is, however, crucial for the way norms matter. First, he argues that there is a 'normativity intrinsic to the law' (Foucault 2007, 56) but this normativity is not necessarily translated from norms or part of a process that defines what norms are. He notes that:

[I]f it is true that the law refers to a norm, and that the role and function of the law therefore - the very operation of the law - is to codify a norm, to carry out a codification in relation to the norm, the problem that I am trying to mark out is how techniques of normalization develop from and below the system of law, in its margins and maybe even against it (Foucault 2007, 56).

The prohibitive mechanism of law works 'in the imaginary' (Foucault 2007,47 ) to define a priori, on the basis of fixed rules, what is the permitted normality (i.e. everything that is not prohibited is allowed). ${ }^{3}$ In contrast, disciplinary mechanisms determine the limits of appropriate behaviour (i.e. complying involves acting only within the prescribed parameters). In this regard, Foucault distinguishes between two processes, normation and normalization:

Disciplinary normalization consists first of all in positing a model, an optimal model that is constructed in terms of a certain result, and the operation of disciplinary normalization consists in trying to get people, movements, and actions to conform to this model, the normal that which is incapable of conforming to the norm. In other words, it is not the normal and the abnormal that is fundamental and primary in disciplinary normalization, it is the norm. I would rather say that what is involved in disciplinary techniques is a normation (normation) rather than a normalization (Foucault 2007, 57).

Disciplinary technologies are based on certain ideal-type norms as predefined standards, which serve as benchmarks of a disciplinary process. Foucault 'realizes that law and discipline have a common starting

${ }^{3}$ See also Macherey's (1991) differentiation between juridical-negative and biologicalpositive models of norms. 
point: neither is based on the descriptive normal but on a prescriptive norm' (Lemke 1997, 190, author's translation). This leads Foucault to conceptualize the process of normalization to define what constitutes the (average) normal. Normalization is conducted by 'apparatuses of security', technologies, and governing techniques that use statistical methods to measure the 'normal distribution' of various indicators of population control. Foucault elaborates that:

In the disciplines, one started from the norm, and it was in relation to the training carried out with reference to the norm that the normal could be distinguished from the abnormal. Here, instead, we have a plotting of the normal and the abnormal, of different curves of normality, and the operation of normalization consists in establishing an interplay between these different distributions of normality (...) These distributions will serve as the norm (Foucault 2007, 63).

Therefore, normalization refers to a process in which norms are constructed as products of perceived distributions of the statistical, average normal. Normalization creates perceptions of 'normal', which create a benchmark that can be used to assess whether certain actors are performing better or worse. Normation, in contrast, is the process through which existing and fixed norms work as standards of conditionality and compliance. This introduces a concept of norms that locates them outside of the stable, ideational, pre-action level. In this alternative view, norms emerge and change in practical contexts; their substance is produced by techniques but they are not defined prior to actions.

Foucault referred in this segment of his lectures to the specific, historical emergence of calculative, statistical techniques that established a sense of the 'average normal' in the 18 th century. If we reconsider contemporary research on norms in this context, it is apparent that the predominant conceptual perspective is based on the model of disciplinary, prescriptive regulation in the broad sense. Although there is a conceptual accommodation of the flexible, constitutive, and constituted qualities of norms, the prevailing approach prioritizes fixing normative meaning at the decision-making level, and ignores the operationalization of norms. This theoretical problem is particularly relevant in settings where decisions about (normative) objectives or programmes are made separately from the operationalization of these decisions - such as by governments, inter- and supra-national organizations, which entail different layers of decisionmaking and implementation.

In particular, the Foucauldian perspective draws attention to how the substance of norms emerges in measuring the population. Before his governmentality lectures, Foucault introduced the notion of 'bio-power' 
(Foucault 1990, 140), which is manifested in 'the disciplines of the body and the regulations of the population' (Foucault 1990, 139). This is important insofar as the viewpoint is redirected from the level of individuals (bodies) to the entire population. Although it is rarely considered in more detail, social constructivist mechanisms such as persuasion, socialization, and diffusion theoretically conceptualize the effects of norms on individuals. This implies that actors either accept or reject specific normative meanings, but neglects conceptualizing transformative feedback from actors to an assumed normative structure. The statistical measurement and subsequent normalization of what is considered 'normality' or 'average normal' establishes the norm in concrete administrative practices - for example, the design and application of indicators. Then the data are 're-translated' to the initial norm-setting (decision-making) level. It is apparent how the average IQ of students, GDP growth or mortality rate can serve as benchmarks of societal normality providing indicators of an optimum, but how are political norms operationalized in this regard? Are indicators simply replacing political processes of norm creation?

Foucault did not explicitly address the operationalization of pre-existing norms in conceptualizing the three mechanisms of prohibition, prescription (normation), and normalization mentioned above. Instead, he maintains a de facto dichotomy of legal, disciplinary normation, and normalization through 'statistical instruments' (Foucault 2007, 58) in his governmentality lectures. However, political or social norms that would be considered disciplinary standards of appropriateness are also operationalized on the basis of statistical assessments that supply the administratively necessary data with which to measure success and failure.

Based on the above discussion, I argue that the (statistical) normal, which is taken as relevant normative substance, is produced in technical processes and normalizes what norms mean in practice. Translating fundamental norms, such as HR, into operational indicators might only define these norms based on what is countable and processable. Taking the 'translatability' (Rose and Miller 2010,280) of rationality, which denotes the ideational construction of the ways and objectives of government (Merlingen 2006, 22; Rose and Miller 2008, 29; see Gordon 1991, 3), and the process of operationalization seriously, however, implies considering to what extent a reformulation, transformation, or even (re-)construction of norms takes place. Further, it should be studied what kind of role-specific technologies and techniques play here. This is also relevant for understanding the relationship between rationality and technology, particularly with regard to the assumption that stable technologies and techniques produce rationalities that is central to my argument.

In this regard, operationalizing norms means recurring on a set of different technologies and techniques of governmentality, examples of which 
are addressed in the relevant literature (Miller and Rose 1990; Dean 1999; Haahr 2004; Walters 2004; Triantafillou 2007; Rose and Miller 2008; Collier 2009). The definitions of (and differences between) technology and technique are rarely made explicit, however, and Foucault used these terms in a rather elusive manner. I consider techniques to be integral parts of technologies, representing macro tools of governing such as reporting, assessments, and evaluations. ${ }^{4}$ Equally, there is a plethora of techniques that constitute technologies of governing. Considering the limitations of this article, I will mainly focus on operationalization through indicators, representing the techniques of quantification and calculation (see Merry and Wood 2015), which are salient parts of global governance's 'governing by numbers' (Miller 2001). A clear definition or even limitation of what technologies and techniques are is, however, counterproductive. In contrast, it is more important to analyse how they work in the practice of governing. The next section considers the role of indicators in the operationalization of norms in more detail.

\section{Operationalization and indicators}

In the context of norms research, my understanding of operationalization assumes that normative objectives are not simply implemented in a neutral fashion using a set of default techniques (see Lascoumes and Le Galès 2007, 3). Instead, techniques, such as statistical methods to quantify social phenomena, produce normative substance; they define problems but also offer solutions, at least implicitly. In other words, a technology's 'properties are indissociable from the aims attributed to it' (Lascoumes and Le Galès 2007, 6). Techniques are vested with normative baggage that stems from the programmatic purpose they were created for. However, in contrast to the position 'that every public policy instrument constitutes a condensed and finalized form of knowledge' (Lascoumes and Le Galès 2007, 11), I emphasize the constitutive role of technologies and techniques that is not fixed a priori, which also renders it necessary to specify the role of norms. Technologies and techniques are therefore developed in certain contexts and for specific purposes, but they are not normatively programmed to simply translate scripts into practice. Rather, instruments produce normative substance aggregated by a constant stream of social data emanating from measuring processes.

How, for example, do political norms matter when countries' conditions and situations are assessed along economic, political, and social dimensions? Regardless of whether actors share a common normative

\footnotetext{
${ }^{4}$ A further discussion of this aspect is theoretically interesting but not central for this article.
} 
understanding of what democracy means, for instance, the techniques used to evaluate, report, and monitor the quality of democracy or governance are largely homogenous. This is at the core of the 'comparative turn' (Martens 2007), pointing to the importance of a limited number of indicators that key international actors share. The construction of these indicators is vital for how norms and objectives are operationalized. Moreover, the processes of data collection used to develop statistical understandings of normality (as normal distribution) produce a particular definition of norms. In this regard, conceptualizations of socialization processes such as the 'the norm life cycle' (Finnemore and Sikkink 1998, 895-96) or the 'spiral model of human rights change' (Risse, Ropp, and Sikkink 1999, 20) that provide influential ideas on the impact of HR norms ignore that the operationalization of norms might produce a very different normativity to the one initially ascribed. The intentions of 'norm entrepreneurs' 'interested in changing social norms' (Sunstein 1996, 909; see Finnemore and Sikkink 1998) could therefore not only be lost but also transformed during translation. In addition, these studies overemphasize the independent character of the internalization process that only requires initial persuasion and acceptance to result in a desirable outcome by default. However, 'the government of oneself' (Foucault 2007, 88) based on 'action at a distance' (Rose and Miller 2010, 278) in the Foucauldian sense necessitates constant monitoring and evaluation.

The process of operationalization, in which normative substance is constructed as functional information (i.e. statistical distributions defining the average normal), works in the direction of fundamental norms and not vice versa. Therefore, no fixed optimal model is used to assess the conditions to which populations should conform. Rather, certain findings are presented as more or less favourable depending on the degree of deviation from the average normal. This is what Foucault considers to be normalization in the strict sense.

To give an example, how does the operationalization of an abstract political objective such as 'good education' work in this regard? The 'Programme for International Student Assessment' (PISA), conducted by the OECD since 2000 , is based on previous OECD initiatives aimed at 'measuring knowledge' in the context of the proclaimed 'knowledge-based economy', which is supposed to strategically link information, education, and knowledge as exploitable resources to promote economic growth and 'maximize performance' (OECD 1996, 7-8). The PISA test scores, scaled according to the 'Rasch Model of Item Response Theory', cover 70 'economies' to date and are only meaningful on a comparative and competitive basis. The rationale is that scaled scores set the OECD average score at 500 with a std. dev. of 100 . The results are visualized in tables for each testing area (maths, science, reading) 
and presented as country rankings (OECD 2015). PISA demonstrates how the uncontested fundamental norm of good education, shared by stakeholders in the decision-making process, is constructed and specified in the implementation phase. In other words, the techniques used to operationalize the norm of 'good education', represented by assessing performance as part of implementing reforms, produce a normativity that is translated into functional terms. The substance of good education is identified using the average normal distribution, which is simply a score of 500. This number, and its monitoring process, turns into the 'make it and break it' point of what is considered as favourable educational policy without providing contextual substance or case-to-case differentiation.

Yet, the operationalization of education in terms of measurement is often provided by specialized institutions that are neither formal part of domestic politics nor involved in implementing policies but still normalize rationalities. According to a European Commission representative: ' $50-60 \%$ of the data for the EU's indicators report for the Lisbon strategy are from the OECD (...) because at the EU level it would cost too much money to develop such instruments like PISA' (cited in Grek 2009, 32). The practice of country reporting produces indicators that display statistical variance but do not result in policies that differ fundamentally, are 'tailor-made' or based on 'joint ownership', to use some global governance keywords. Calls for 'modernization', 'democratization', 'liberalization', or 'development' are made on the grounds of perceptions of statistical normality largely derived from conditions in western or highly developed industrialized states. When it comes to implementing policy programmes that are supposed to promote necessary reforms to create these conditions, the question is not whether there are shared interpretations of fundamental political norms, but what the 'indicatorisation' (Crothers 2006) of their economic, social, and political dimensions means for normative governance (see Merry 2011).

How do GDP growth, the rate of school enrolment or per capita income, to name a few popular indicators, relate to normative objectives? Governing by numbers is an important characteristic of global governance that aims to transform societies (see Rose 1999; Merry 2011; Hansen and Mühlen-Schulte 2012, 197). This approach uses indicators to justify reforms and to serve as the basis of rigorous monitoring practices. In other words, governing by means of quantifications also denotes a governing of numbers - assessing success and failure becomes a numerical comparison and political responses are focussed on changing numeric indicators. At the very least, this entails the intrinsic risk of perceiving only those problems and solutions that fall into the narrow scope of what is statistically displayed. The feedback of supposedly normatively neutral and exact 
numeric indicators to the decision-making level contributes to naturalizing requirements, needs and conditions thereby purporting unquestioned truths about how to handle issues. The 'problematization (...) that introduces something into the play of true and false and constitutes it as an object for thought' (Foucault 1999, 257) is inherently linked to a limited range of seemingly inevitable responses. In other words, the 'problem' is perceived from the end of techniques in the first place. This also implies that programmatic solutions, such as the shorthand response of privatization in development cooperation, only allow those particular problems to occur that are inherent to their perceptual limits of measurement. My point is here not to argue for the general irrelevance of indicators. Rather, I emphasize the normative implications of technical processes that are widely perceived as neutral operationalization devices.

Scholarship on neoliberal governmentality criticizes how quantitative methods economize the political dimension and thereby manage populations based on the paradigm of optimized performance. Gane argues, for instance, that the neoliberal 'marketization of the state' is 'about intervention and regulation with the aim of injecting market principles of competition into all forms of social and cultural life' (Gane 2012, 630-31). The crucial transition from liberal to neoliberal technologies does therefore not primarily concern the assumed retreat of the state based on deregulation and privatization, but is rather designed to implement principles of competition and evaluation in political, public domains such as education and health systems. Here, the process termed 'the "governmentalization" of the state' (Foucault 2008, 109) provides for an important connotation, particularly with respect to the global level: the expansion of governmental interventions, initiated by actors of global governance, does not lead to the worldwide spread of a very specific normative meaning but to the global dissemination of a certain administrative order. This model and its relevant technologies result from incorporating economic-administrative principles and methods into the political dimension.

However, normativity and the political act do not disappear, contrary to what the 'marketization' or neoliberalization of global affairs understood as explicitly apolitical processes suggest. In fact, while the intensification of economic transactions and the harmonization of relevant procedures and standards are certainly key aspects of the idea of globalization, the worldwide proliferation, codification, and institutionalization of 'universal' norms deepens at the same time. In this regard, it is important to consider how neoliberal technologies and the alleged promotion of fundamental norms in global governance are combined. The logic of functionality that appears in the disguise of 'indicatorizing' governing programmes manifests itself in homogeneous technical approaches. Furthermore, the rationality of 
the governance toolbox defines what kinds of problems are perceived in the first place. The appropriateness, legitimacy, or contestation of normative meaning becomes irrelevant - diverging understandings of democracy are not important if procedures for measuring, quantifying, and ranking the quality of democratization have the same shape and funding guidelines only match up with these instruments.

The literature on indicators and governmentality has provided for significant insights into the relation of power and knowledge in the field of 'technical' governance (e.g. Löwenheim 2008; Busse 2015). However, a research gap remains: how do indicators relate to norms that are widely conceptualized as pre-existing normative standards of governing? If indicators are the decisive link between decision-making and implementation, this question becomes even more important. The following section illustrates the operationalization of fundamental norms using the EU's HR policy as an example. While this section cannot provide a nuanced analysis of the EU's HR instruments such as the 'European Instrument for Democracy and Human Rights' (EIDHR), the objective is to give an overview of how the practice of operational translation unfolds as well as to highlight its normative implications. In that, the following section is also meant to encourage further comparative and more detailed studies of HR instruments and other technologies and techniques in global governance to understand the role of (fundamental) norms in implementation practices.

\section{Operationalizing HR: the indicatorization of fundamental norms}

The promotion and defence of HR is at the heart of political 'good governance'. Key institutions and organizations such as the EU or the United Nations (UN) emphasize the importance of promoting HR when it comes to development cooperation or external relations. HR in terms of political conditionality that defines specific requirements, demands, and expectations in return for financial-economic opportunities therefore occupy a central position in external governance models. How are HR operationalized technically? Generally, the operationalization of these 'fundamental norms' is based on constructing indicators, measuring the performance of specific actions supposed to promote HR. As noted before, indicators comprise compressed data as representations of social phenomena that are not directly measurable. Abstract norms such as HR are therefore operationalized as the aggregate of certain conditions, such as the absence of torture, school enrolment rates of girls, or free elections. Furthermore, indicators can represent a process or an outcome, depending on whether they are supposed to measure a development or a result. 
As in the case of different types of operationalization, indicators are designed for different purposes. For example, Raworth $(2001,111)$ differentiates between quantitative and qualitative indicators in that the former provide numeric information, while the latter imply judgements. This suggests a procedural definition and dichotomization of measurement and monitoring: ' $[\mathrm{w}]$ hile the outcome of monitoring is a judgement, the outcome of measurement is not' (Starl et al. 2014, 17). However, this distinction reproduces techniques of quantification as part of neutral operations. Creating indicators, the process of monitoring itself as well as deciding what counts also contains judgements. This reflects the general argument that operationalization is basically an interpretative action, regardless of whether it comprises indicators or not. To come back to HR, applying indicators in the sense of numerical data used in statistics represents this ideal of objective measurement that allows for quantifying, calculating, and comparing results. This approach to HR is reflected in the widespread usage of the 'enjoyment' concept that assesses the degree to which specific rights are 'enjoyed' by the population (Raworth 2001, 119). It comes close to the predominant focus of development cooperation evaluations on social-economic conditions such as unemployment rates, literacy rates, life expectancy, or rates of inflation that are criticized for comparing societal development and performances without considering differences in the capacity of countries (McInerney-Lankford and Otto-Sano 2010, 19). While the possible divergence between abstract HR and indicators is evident in terms of the normative meaning that emerges at different points, the function of HR indicators as part of operationalization requires additional scrutiny.

\section{Indicatorizing $H R$}

The EU is one of the major global actors involved in promoting HR and democracy. The Treaty on European Union (TEU) states in Article 21, 2 that

the Union's action on the international scene shall be guided by the principles which have inspired its own creation, development and enlargement and which it seeks to advance in the wider world: democracy, the rule of law, the universality and indivisibility of human rights and fundamental freedoms, respect for human dignity, the principles of equality and solidarity and respect for the principles of the United Nations Charter and international law (European Union 2012).

These normative objectives are not only anchored in the TEU, but are also reproduced as key elements of the EU's discourse on normative legitimacy in its external actions. In 2012, the 'EU Strategic Framework and 
Action Plan on Human Rights and Democracy' (11855/12) was adopted, which provides for the first common EU framework document to coordinate and streamline its approach to HR. Here, the EU declares that it is determined to 'promote human rights in all areas of its external action without exception' (Council of the European Union 2012, 2). This objective lead, inter alia, to adopting financial instruments, such as the EIDHR in 2006. For the initial period of 2007-2013, the EIDHR's budget was €1.104 billion (European Commission 2015c), comprising €1.332 billion for the 2014-2020 period (European External Action Service 2014, 24). The EU's HR policy is therefore implemented by substantial funding instruments, which require an operationalization of norms not least to comply with existing evaluation procedures. Basically, this bureaucratic demand for HR indicators originates in the administrative processes for allocating funding and assessing/evaluating the performance of allocated means. This is also linked to the structural separation of funder and implementer, with the former often holding a superior position as knowledge-provider and agenda-setter. However, regardless of the HR conception of the funder, what HR promotion is and how to understand HR emerges in the operationalization process.

For example, under the leadership of EU delegations in specific countries, grants funded by the EIDHR are allocated 'through competitive calls for proposals' (European Commission 2015b). The EIDHR allocation practice not only requires data for kick-starting the initial funding process but also in the evaluation phase. The EIDHR will undergo a mid-term review in 2017 and the report to be released 'will focus on the achievement of the EIDHR objectives by assessing indicators measuring the results delivered and the EIDHR's efficiency' (European Commission 2015b). For this purpose, the EIDHR comprises five objectives: support to HR and HR defenders; support to other EU HR priorities; support to democracy; EU election observation; support to targeted key actors and processes, including international and regional HR instruments, and mechanisms; and support measures and unallocated reserve (European Commission 2015b). The annex of the 'Instrument for Democracy and Human Rights Worldwide Multiannual Indicative Programme (2014-2017)' document lists several indicators for each objective and partly addresses how results shall be evaluated by using external sources such as data provided by the UN's Office of the High Commissioner for Human Rights. The EU almost exclusively focusses on numerically processed outcomes. For example, the 'number of advocacy, awareness raising, and capacity building activities supported', the 'average time it takes to process requests for emergency support', or the 'number of Human Rights Defenders (individual) being protected' are taken as baselines for constructing evaluation indicators (European External Action Service 2014, 26). 
This quantitative technique matches with existing approaches to evaluation, accountability, and administrative efficiency. However, the indicators mentioned above fail to provide deeper insights into the procedural dimension of HR promotion apart from delivering snapshots of a numerically measured situation at a specific point in time. First, the substance of HR is constructed as an active dimension. This means that the evaluation technique is not based on a definitive, explicit understanding of what HR are. Instead, the amount or efficiency of HR actions serve as proxies for more or less favourable situations. Second, measuring such numbers allows for determining a normal distribution of $\mathrm{HR}$, for example, for development countries, and to compare it with the statistical normality of EU members. A normalization in this sense would then entail activities aimed at bringing the former normality in line with the latter. However, this is not the case. In other words, the EU's approach to making HR operational at this stage is not based on fixed norms used as benchmarks to assess against a HR optimum, as it is the case with disciplinary measures. At the same time, the process of normalization that forms part of the logic of operationalizing HR is not systematically applied. This is noteworthy because it points to a theoretical and a practical problem: theoretically, the EU's fundamental or constitutional political norms, enshrined in Article 21 of the TEU, are therefore reconstructed in terms of different but largely random proxy indicators. The normative substance emerging here is hence vague and not clearly linked to this specific set of fundamental norms. This challenges theoretical concepts using these fundamental norms as an analytical starting point to judge whether HR are promoted successfully or not. The practical problem concerns the operationalization of HR by providing insights into how a situation compares to another, while clear concepts of optimal conditions and situations are lacking. The ambivalence that is a central feature of judgements contradicts the need of fixed evaluation standards, which the EU's approach actually requires and the dominant understanding of fundamental norms in IR implies.

Considering the quantification of 'human rights defenders', it is unclear whether a higher number of protected 'defenders' constitutes a failure or a success of EU policy. Was the situation of HR defenders enhanced or exacerbated through the EU's action? Furthermore, only elaborate and detailed qualitative studies of individual cases could provide for information on the impact of a specific action. In fact, there is evidence that the intervention of western states in terms of political-economic pressure, the funding of activities, or media attention can create a backlash on HR actors in certain situations (see Bukovská 2008; Terman 2013). Apart from the methodological and conceptual problems that emerge when designing indicators to measure social phenomena, such as the fact that most 
HR indicators fail to measure the intensity and quality of violations (see Landman 2004), a related but more basic challenge concerns the operationalization of universal norms.

\section{The impossibility of universality and the inevitability of normativity}

The EU's 2012 Strategic Framework document declares 'promoting the universality of human rights' to be one of the central objectives of its HR policy. It states that ' $[\mathrm{t}]$ he EU will speak out against any attempt to undermine respect for the universality of human rights' (Council of the European Union 2012, 2). While this position is certainly in line with the mainstream international legal framework as well as democratic practices and mirrors the logic associated with the role of fundamental norms, how can the assumed universal normativity be operationalized in order to translate it accurately (see Raworth 2001, 118; O'Neill 2005; Merry and Wood 2015, 206)? Indicators are neither universally applicable nor are they capable of reproducing social processes in their totality. Moreover, there are no universally accepted standards (and thereby no specific normativity) that would define what kind of indicators are suitable for measuring HR. While there is a tendency to recur to similar indicators, establishing a global standard of measurement, the actual operationalization is at the discretion of administrative procedures performed by a limited number of actors. The resulting broad interpretation of what the substance of HR is might or might not match the intentions of those having decided on a political programme in the first place.

Indicators not only produce normative substance by defining specific aspects as relevant for HR, they also set limits as to what is perceivable in the first place. In other words, 'to make something known it must be countable, but if it has not already been translated into commensurable and quantifiable terms, it is difficult to count and may remain unnoticed and uncounted' (Merry and Wood 2015, 205). The increasing need for data and the streamlining of governance models that rely heavily on indicators, preferably quantitative ones, has not least lead to an increased dependence on the availability of data. Therefore, it matters not only whether initial intentions can be adequately translated by indicators but also what kind of scenarios indicators construct, considering that less developed countries often lack the capacities or willingness to provide the required amount and quality of data necessary for this system of governmentality (see Jerven 2012).

Politicized information, such as HR data, depends on available, objective sources, and material. But what kind of knowledge do actors such as the European Commission or the European External Action Service use? 
The EU's monitoring and evaluation material (in the form of Progress Reports) rarely provides insights into how the processed information was acquired. Occasionally, there are references to secondary knowledge providers such as the OECD, the World Bank, and non-governmental actors such as Amnesty International, Freedom House, or Transparency International. The Freedom House index, for example, works with two simple numerical ratings for each country, from one to seven for political rights and civil liberties, with one representing the freest and seven the least free. While a diversification of sources is certainly required to obtain a broader range of data, the EU fails to problematize whether the substance of HR promotion matches with the HR understanding of these sources. This is not visible by considering HR on a scale from one to seven. In adopting existing standards, the EU therefore also, by default, accepts the problem-solution concept that is implicit in the decisions of what and how to measure, a decision that the Union has not made by itself.

If, for instance, the substance of equality is constructed based on indicators that calculate the average numbers of educational degrees, of sexual harassment, of psychosocial health consultations, of the average income, employment rates, or of numbers of perceived pregnancy discrimination, equality is identified by way of the average normal distribution, which consists of specific scores in numeric terms. Whether country situations in terms of equality can be considered normatively 'good' is then judged on the basis of national and global comparative rankings that display favourable or unfavourable performances. The operationalization of HR in the way described is based on default approaches of measurement accepted as appropriate. This ascribes techniques a substantial role in defining the substance of norms. However, the feedback loop that connects the operationalization sphere with other levels of norm construction or deliberation is also subject to the political processing of this substance. To put it differently, norms might be interpreted in specific terms in the operationalization process; this interpretation, however, does not ultimately stabilize meaning but is again transformed in a process that politicizes measurement.

\section{The politicization of measurement}

In the previous sections, I have argued for focussing on whether and how normative substance emerges in the 'technical' operationalization of HR. While the importance of considering the constructedness of norms on this level is apparent, the implications of this process emerge out of different layers of politicization. Although techniques hold an influential structuring position in my concept of governmentality, the role of indicators is also part 
of political agency. Even if indicators provide for specific constructions of normative substance, the inclusion of this meaning in decision-making procedures is a political act. The interpretative feedback of indicators as the substance of fundamental norms in this type of operationalization depends on the technical but also on the judgemental processing that occurs in monitoring activities. How indicators inform norms is partly shaped by the specific programme they are meant to operationalize. This points to the hybrid function of indicators linking decision and implementation through operationalization. Normalizing perceptions takes place in assessment procedures applying a range of standard indicators that focus on the pre-defined average as the desirable normality. However, this is not necessarily an unreflective act, but often part of the politics of measurement.

Abstract norms such as HR require some form of operationalization to give them practical relevance. The decision to operationalize and to measure qualitative phenomena is, however, subject to methodological and ideological controversies. The approach actors such as the EU take comes across as either indifferent to or unaware of the power of operationalization - given that the crucial questions of why (and how) to measure are never substantially addressed. Although the theoretical controversy between problem-solving and critical theory (Cox 1981) mirrored here points to the importance of epistemological awareness, elaborations by, or conversations between the administrative-governmental and the theoretical-academic dimensions that offer competing viewpoints on how to operationalize norms are limited.

Accommodating the political dimension of measurement also implies that procedures and techniques can become standards of good governance themselves. It is noted on examination in the sense of assessment that 'the examination creates a new discursive environment in which new standards of normalcy are determined' (Löwenheim 2008, 262). This could result in a situation where the willingness of target states to comply with assessment procedures and to use 'approved' techniques replace the more fundamental, political question of what kind of normative substance should be promoted. The extent to which governments comply with a concept of normality would then largely be defined by their compliance with administrative normality and by their participation in a range of programmes, not only with regard to HR. Resistance to these measurement activities results in several disadvantages, most importantly restricted funding opportunities. This is not necessarily the outcome of deliberate decisions to sanction failing compliance but simply the result of a 'missing' statistical identity. In other words, HR (actors) that cannot be assessed and therefore funded are de facto non-existent and the same applies to HR violators that are only sanctioned when they are detected by assessment criteria constructed by techniques. In this respect, technicalstatistical normality could replace normativity. 
Furthermore, the subjectification (subjectivation) inherent to the indicatorization process, apparent in constructions such as 'human rights defender' or the categories of 'victim' and 'violator' (Sokhi-Bulley 2011, 141), raises the question what kind of subjectivities are produced. The EU operates with an opaque and implicit understanding of what constitutes a victim, a violator, or a defender of $\mathrm{HR}$, which are merely used as categories to quantify success. Considering the distinction between an enjoyment and obligations approach, '[r]ights are seen as one side of a normative relationship between right-holders and obligation-bearers' (O'Neill $2005,430)$. Categorizations such as victim, which are functional parts of the 'protection process' of funding agencies, construct normative subject positions that fix individuals within specific categories. The practice of HR operationalization can lead to a culture of blame, complaint, and constant state control (O’Neill 2005), a 'victimization' (Bukovská 2008, 10) of the allegedly passive and powerless that are denied agency in this model.

What I want to draw attention to here is not least that norms as abstract constructs are usually defined without reference to the subjects they ought to protect. This does not only mean that the content of these norms is substantiated in the operationalization process, but that the subjectification inherent to clarifying who is a victim, who is an offender, and who acts as a defender of HR likewise takes place there. However, the EU's approach shows that the construction of subjects is mostly an implicit process, a by-product of mundane criteria that are mainly concerned with defining who is eligible for funding. In this regard, deciding about what qualifies as a project, as an action, or as a victim and defender of HR worth receiving financial support, a step placed before the quantification process, remains remarkably out of sight. This is particularly noteworthy because the numerical evidence of success or failure evaluated at a later point is based on these categories.

In the case of the EIDHR, country calls and global calls for proposals 'are selected by the Commission in consultation with its local delegations' (European Commission 2015a). The EU delegations in relevant countries release guidelines for grant applicants that comprise specifications on eligibility criteria. It is beyond the scope of this article to consider these requirements in more detail. However, it is apparent how formal criteria alone are already decisive for the success of applications and, in fact, for defining subjects and actions. The guidelines also contain a non-exhaustive and vague list of examples of types of actions that are eligible for funding, such as 'activities for strengthening of existing civil society' or 'awareness raising public communication' (e.g. EU Delegation to Namibia 2013, 5-6). The lack of specificity is remarkable since this is the very point where HR are supposed to be operationalized. This demonstrates, again, how the 
substance of these norms is constructed in individualized practices that areeven on this level - not based on transparent and elaborate definitions of what HR are. Further research investigating the concepts and the understanding of HR emerging on the micro-level through detailed participant observation of institutional practices is clearly necessary.

Moreover, in the logic of the EU, efficiently managing instruments of HR and their technical procedures require a certain extent of professionalization. The aforementioned construction of weak and passive victims is intensified by the fact that individuals whose rights are violated depend on a professional organization to report, appeal, and apply in their name - even if these organizations are based in western capitals and only have very limited direct access to the individuals and the processed data as a whole (see Bukovská 2008, 11).

In sum, this section presented a theoretical argument about the conceptualization of norms in IR and an empirical one about the practice of operationalizing norms. In theoretical regards, it showed how the operationalization of norms is a normative act that fills abstract HR with substance. The analysis of the EU's HR policy suggests that the emerging normative substance is unspecific and constructed on the individual level. This is theoretically important because it confirms that operationalization in fact defines what norms are, although often in a way that is less clear and easily detectable than analytical approaches to norms research would desire. Defining the meaning of norms is an incredible fragmented, local, and complex process involving various actors and techniques beyond the operationalization in terms of measurement described here. This largely contests widespread assumptions about how the role of norms is conceptualized in IR. In practical regards, it implies that actors such as the EU are funding actions and promoting objectives that are likely to be de-linked from the intentions of those deciding upon these actions in the first place.

\section{Conclusion}

Research on norms, often framed by competing logics of actions, mainly focusses on why and how norms are adopted. Presenting a contrasting perspective, this article discussed the (technical) operationalization of norms, thereby shedding light on the neglected implications of how abstract norms are implemented in practices. I argue that the operationalization of norms through techniques such as indicatorization does not only lead to a reconstruction of their substance - symbolized by the transformations taking place in translation processes - but also that the meaning of abstract norms is, in fact, only produced in technical procedures. The feedback loop 
of norm operationalization, filling existing but diffuse norms with substance, provides a conceptual link between the structured and structural side of norms. In this approach inspired by governmentality studies, techniques play a decisive but understudied role for understanding the normativity of norms that might depart from the intentions or normative objectives initially held by norm-setters. Departing from the focus on the decision-making level of conventional norms research, this article zoomed in on indicators at the core of governance techniques of measurement. These techniques as perceived rational tools work as a common denominator, regardless of normative divergence or convergence. The emerging instrumental homogeneity does not only refer to the broad agreement on the usefulness of measuring and monitoring, but also to other techniques widely applied in the fields of development policy, democracy support, HR promotion, or infrastructural reforms. Normative disputes or the question whether decisions are in fact informed by the same normative meaning are of secondary importance if techniques for operationalizing norms are uncontested. In that, a technological-procedural regime of best practices is fundamental to approaches of global governance.

Privileging the process of norm operationalization allows for conceptualizing the origin of norms in the context of their functional management, instead of keeping these dimensions separate and sequential. Norms such as HR are certainly present in treaties, speeches, programmes, or key documents, which explains their dominant role in IR. However, we should also consider that the prevalence of indicator-driven approaches necessitates devoting more attention to techniques of governing since they provide conditions of possibility for rationalities to emerge. In other words, normative substance is created through the instrumental operationalization of norms. The adoption and reproduction of a range of technical solutions based on instruments significantly narrows the agenda of approaches to the governing of economic, political, and social phenomena.

Instruments of governance are not neutral and objective tools that merely translate (normative) governmental objectives into practice. The EU's HR policy discussed here is an example of how diffuse and abstract norms are operationalized, mainly for funding purposes. The allocation of substantial financial means, such as the EIDHR, follows existing practices of reporting, evaluating, and monitoring based on indicators. What counts as favourable or less favourable HR conditions is supposed to be measured by these indicators. However, the design and selection of indicators is opaque and decoupled from the political decision-making process. In other words, what, how, and why phenomena are measured is unclear and left to the discretion of the relevant expert bureaucracy. The main finding of this empirical illustration is therefore that the entire process of normative 
governing is unsystematic and improvised. The meaning of HR is neither elaborated nor stabilized on the codification or decision-making level; nor is their substance clearly defined in their operationalization. While indicators provide an intuitive conceptualization of what HR could mean in the practice of governing, and thereby produce a certain normativity, they appear to be formulated on a random basis.

Highlighting the practice of operationalization contests the assumed ontological priority of normative structures informing actions. However, the normative feedback loop conceptualized in this article is not meant as a mere reversal of the decision-action sequence. Instead, the objective is to draw attention to the reconstruction of rationalities by techniques as a central part of operationalizing norms without overemphasizing the autonomous agency of materiality. Nevertheless, the social constructivist need for 'bracketing' - either focussing on the constructed or structuring qualities of norms - moves to the background if actions are not conceptualized as informed by stable norms but as implemented through dominant instruments. This contributes to refining and revaluing the understanding of instruments as fundamental to the normative substance of international relations.

This article highlights the general importance of norm operationalization and the need for research on different varieties of norms and how they operate in practice. While the empirical illustration focusses on the operationalization of HR in the EU's administrative bureaucracy, this conceptualization applies to other areas and actors as well. A comprehensive understanding of what norms are (and how they matter) therefore requires extensive, detailed analyses instead of parsimonious models.

\section{Acknowledgement}

The author is grateful to the editors and three anonymous reviewers of International Theory for their extensive and insightful comments. Special thanks to Ingvild Bode for commenting on earlier versions of this article and to Thomas Ambrosio for providing valuable feedback at the WISC 2014 in Frankfurt, Germany.

\section{References}

Acharya, Amitav. 2004. "How Ideas Spread: Whose Norms Matter? Norm Localization and Institutional Change in Asian Regionalism." International Organization 58(2):239-75.

Adler, Emanuel, and Vincent Pouliot. 2011. "International Practices.” International Theory 3(1): $1-36$.

Apter, Emily. 2001. “Balkan Babel: Translation Zones, Military Zones.” Public Culture 13(1): 65-80. 
Archibugi, Daniele. 1992. "Models of International Organization in Perpetual Peace Projects." Review of International Studies 18(4):295-317.

Barry, Andrew. 2013. "The Translation Zone: Between Actor-Network Theory and International Relations.” Millennium - Journal of International Studies 41(3):413-29.

Best, Jacqueline, and William Walters. 2013a. “'Actor-Network Theory' and International Relationality: Lost (and Found) in Translation.” International Political Sociology 7(3): 332-334.

Best, Jacqueline, and William Walters. 2013b. "Translating the Sociology of Translation." International Political Sociology 7(3):345-49.

Bode, Ingvild. 2015. Individual Agency and Policy Change at the United Nations. London and New York: Routledge.

Börzel, Tanja, and Thomas Risse. 2012. "From Europeanisation to Diffusion. Introduction." West European Politics 35(1):1-19.

Börzel, Tanja, and Etel Solingen. eds. 2014. "The Politics of International and Regional Diffusion." Special Issue of International Studies Review 16(2).

Bueger, Christian, and Felix Bethke. 2014. "Actor-Networking the 'Failed State' - an Enquiry into the Life of Concepts." Journal of International Relations and Development 17(1): 30-60.

Bukovská, Barbora. 2008. "Perpetrating Good: Unintended Consequences of International Human Rights Advocacy." SUR - International Journal on Human Rights 9:7-21.

Busse, Jan. 2015. "The Biopolitics of Statistics and Census in Palestine." International Political Sociology 9(1):70-89.

Checkel, Jeffrey T. 2001. "Why Comply? Social Learning and European Identity Change." International Organization 55(3):553-88.

Collier, Stephen J. 2009. "Topologies of Power: Foucault's Analysis of Political Government Beyond 'Governmentality'." Theory, Culture \& Society 26(6):78-108.

Council of the European Union. 2012. "EU Strategic Framework and Action Plan on Human Rights and Democracy. 11855/12." Luxembourg. Accessed October 19, 2015. http:// www.consilium.europa.eu/uedocs/cms_data/docs/pressdata/EN/foraff/131181.pdf.

Cox, Robert W. 1981. "Social Forces, States and World Orders: Beyond International Relations Theory." Millennium - Journal of International Studies 10(2):126-55.

Crothers, Charles. 2006. "The Development of Indicators in New Zealand: Indicatorisation. Paper for Social Indicators (WG06) Stream ISA Durban 2006.” Accessed November 16, 2015. http://www.soc.duke.edu/resources/sinet/papers06/Crothers.pdf.

Dean, Mitchell. 1999. Governmentality: Power and Rule in Modern Society. London: SAGE.

EU Delegation to Namibia. 2013. "European Instrument for Democracy \& Human Rights (EIDHR): Country-Based Support Schemes (CBSS) NAMIBIA.” Accessed October 28, 2015. http://eeas.europa.eu/delegations/namibia/documents/funding_opportunities/ eidhr_cbss_namibia_guidelines_en.pdf.

European Commission. 2015a. "EIDHR: Apply for a Grant." Accessed October 28, 2015. http://www.eidhr.eu/funding.

European Commission. 2015b. "EIDHR: Open and Future Calls for Proposals." Accessed October 28，2015. http://www.eidhr.eu/side-panels/funding/open-and-future-calls-forproposals.

European Commission. 2015c. "EIDHR: What is EIDHR?" Accessed October 28, 2015. http:// www.eidhr.eu/whatis-eidhr.

European External Action Service. 2014. "Instrument for Democracy and Human Rights Worldwide Multiannual Indicative Programme (2014-2017).” Accessed October 20, 2015. http://eeas.europa.eu/human_rights/docs/eidhr-mip-2014-2017_en.pdf. 
European Union, Treaty on European Union (Consolidated Version), Treaty of Maastricht, 7 February 1992, Official Journal of the European Communities C 325/5; 24 December 2002. Finnemore, Martha, and Kathryn Sikkink. 1998. "International Norm Dynamics and 1050 Political Change." International Organization 52(4):887-917.

Finnemore, Martha, and Stephen J. Toope. 2001. “Alternatives to 'Legalization': Richer Views of Law and Politics." International Organization 55(3):743-58.

Foucault, Michel. 1990. The History of Sexuality, Volume I: An Introduction. New York: Vintage Books.

Foucault, Michel. 1999. Politics, Philosophy, Culture: Interviews and Other Writings. New York and London: Routledge Chapman \& Hall.

Foucault, Michel. 2007. Security, Territory, Population. Lectures at the Collège de France 1977-1978. Basingstoke: Palgrave Macmillan.

Foucault, Michel. 2008. The Birth of Biopolitics. Lectures at the Collège de France 1978-1979. Basingstoke: Palgrave Macmillan.

Gane, Nicholas. 2012. "The Governmentalities of Neoliberalism: Panopticism, Post-Panopticism and Beyond." Sociological Review 60(4):611-34.

Gordon, Colin. 1991. "Governmental Rationality: An Introduction." In The Foucault Effect: Studies in Governmentality, edited by Graham Burchell, Colin Gordon, and Peter Miller, 1-51. Chicago, IL: Chicago University Press.

Grek, Sotiria. 2009. "Governing by Numbers: The PISA 'effect' in Europe.” Journal of Education Policy 24(1):23-37.

Haahr, Jens Henrik. 2004. “Open Co-Ordination as Advanced Liberal Government.” Journal of European Public Policy 11(2):209-30.

Hansen, Hans Krause, and Arthur Mühlen-Schulte. 2012. "The Power of Numbers in Global Governance." Journal of International Relations and Development 15(4):455-65.

Hurd, Ian. 2008. "Constructivism." In The Oxford Handbook of International Relations, edited by Christian Reus-Smit, and Duncan Snidal, 298-316. Oxford: Oxford University Press.

Jepperson, Ronald W., Alexander Wendt, and Peter J. Katzenstein. 1996. "Norms, Identity and Culture in National Security." In The Culture of National Security: Norms and Identity in World Politics, edited by Peter J. Katzenstein, 33-75. New York: Columbia University Press.

Jerven, Morten 2012. "Briefing: For Richer, for Poorer: GDP Revisions and Africa's Statistical Tragedy." African Affairs 112(446):138-47.

Lahire, Bernard. 1998. The Plural Actor. Cambridge: Polity.

Landman, Todd. 2004. "Measuring Human Rights: Principle, Practice and Policy." Human Rights Quarterly 26(4):906-31.

Lascoumes, Pierre, and Patrick Le Galès. 2007. "Introduction: Understanding Public Policy through its Instruments - From the Nature of Instruments to the Sociology of Public Policy Instrumentation." Governance 20(1):1-21.

Lemke, Thomas. 1997. Eine Kritik Der Politischen Vernunft: Foucaults Analyse Der Modernen Gouvernementalität. Hamburg: Argument.

Lemke, Thomas. 2015. "New Materialisms: Foucault and the 'Government of Things'." Culture \& Society 32(4):3-25.

Löwenheim, Oded. 2008. "Examining the State: A Foucauldian Perspective on International 'governance Indicators'." Third World Quarterly 29(2):255-74.

Lundborg, Tom, and Nick Vaughan-Williams. 2015. "New Materialisms, Discourse Analysis, and International Relations: A Radical Intertextual Approach.” Review of International Studies 41:3-25. 
Macherey, Pierre. 1991. "Für Eine Naturgeschichte Der Normen." In Spiele Der Wahrheit. Michel Foucaults Denken, edited by François Ewald, and Bernhard Waldenfels, 171-92. Frankfurt am Main: Suhrkamp.

March, James G., and Johan P. Olsen. 1989. Rediscovering Institutions: The Organizational Basis of Politics. New York: Free Press.

March, James G., and Johan P. Olsen. 2004. "The Logic of Appropriateness.” WP 04/09, ARENA Working Papers, Oslo.

Martens, Kerstin. 2007. "How to Become an Influential Actor - The 'Comparative Turn' in OECD Education Policy." In New Arenas of Education Governance - The Impact of International Organisations and Markets on Educational Policymaking, edited by Kerstin Martens, Alessandra Rusconi, and Kathrin Leuze, 40-56. Basingstoke: Palgrave Macmillan.

McInerney-Lankford, Siobhán, and Hans Otto-Sano. 2010. "Human Rights Indicators in Development: An Introduction.” World Bank Study, Washington, DC. Accessed October 16, 2015. http://siteresources.worldbank.org/EXTLAWJUSTICE/Resources/HumanRights WP10_Final.pdf.

Merlingen, Michael, and Rasa Ostrauskaite. 2006. European Union Peacebuilding and Policing : Governance and the European Security and Defence Policy. London and New York: Routledge.

Merry, Engle Sally. 2011. "Indicators, Human Rights, and Global Governance." Current Anthropology 52(suppl. 3):83-95.

Merry, Sally Engle, and Summer Wood. 2015. "Quantification and the Paradox of Measurement: Translating Children's Rights in Tanzania.” Current Anthropology 56(2):205-29.

Miller, Peter. 2001. "Governing by Numbers: Why Calculative Practices Matter." Social Research 68(2):379-96.

Miller, Peter, and Nikolas Rose. 1990. "Governing Economic Life.” Economy and Society 19(1): 1-31.

Nexon, Daniel H., and Vincent Pouliot. 2013. “'Things of Networks': Situating ANT in International Relations." International Political Sociology 7(3):342-45.

O’Neill, Onora. 2005. “The Dark Side of Human Rights.” International Affairs 81(2):427-39.

OECD. 1996. The Knowledge-Based Economy. OCDE/GD(96)102. Paris: OECD.

OECD. 2015. "OECD About FAQ.” Accessed November 2, 2015. http://www.oecd.org/pisa/ aboutpisa/pisafaq.htm.

Payne, Geoff, and Judy Payne. 2004. Key Concepts of Social Research. London: Sage.

Pouliot, Vincent. 2008. "The Logic of Practicality: A Theory of Practice of Security Communities." International Organization 62(2):257-88.

Raworth, Kate. 2001. "Measuring Human Rights.” Ethics \& International Affairs 15(1): 111-31.

Risse, Thomas. 2000. "Let's Argue: Communicative Action in World Politics.” International Organization 54(1):1-39.

Risse, Thomas, and Kathryn Sikkink. 1999. "The Socialisation of Human Rights Norms into Domestic Practices: Introduction." In The Power of Human Rights: International Norms and Domestic Change, edited by Thomas Risse, Stephen Ropp, and Kathryn Sikkink, 1-38. Cambridge: Cambridge University Press.

Risse, Thomas, Stephen Ropp, and Kathryn Sikkink. 1999. The Power of Human Rights: International Norms and Domestic Change. Cambridge: Cambridge University Press.

Rose, Nikolas. 1999. Powers of Freedom: Reframing Political Thought. Cambridge: Cambridge University Press.

Rose, Nikolas, and Peter Miller. 1992. "Political Power Beyond the State: Problematics of Government.” British Journal of Sociology 2(43):173-205. 
Rose, Nikolas, and Peter Miller. 2008. Governing the Present: Administering Economic, Social and Personal Life. Cambridge: Polity.

Rose, Nikolas, and Peter Miller. 2010. "Political Power Beyond the State: Problematics of Government." The British Journal of Sociology 61(suppl. 1):271-303.

Schimmelfennig, Frank. 2000. "International Socialization in the New Europe: Rational Action in an Institutional Environment." European Journal of International Relations 6(1):109-39.

Sokhi-Bulley, B. 2011. "Governing (Through) Rights: Statistics as Technologies of Governmentality." Social \& Legal Studies 20(2):139-55.

Starl, Klaus, Veronika Apostolovski, Isabella Meier, Markus Möstl, Maddalena Vivona, and Alexandra Kulmer. 2014. "Baseline Study on Human Rights Indicators in the Context of the European Union.” FRAME Fostering Human Rights among European Policies, Work Package No. 13, Deliverable No. 1. Graz. Accessed October 19, 2015. http://www.fp7frame.eu/wp-content/materiale/reports/12-Deliverable-13.1.pdf.

Sunstein, Cass R. 1996. “Social Norms and Social Roles.” Columbia Law Review 96(4):903-68.

Terman, Rochelle. 2013. "Backlash: The Unintended Consequences of Western Human Rights Intervention.” 50.50 Inclusive Democracy. Accessed October 20, 2015. https://www. opendemocracy.net/5050/rochelle-terman/backlash-unintended-consequences-of-westernhuman-rights-intervention.

Triantafillou, Peter. 2007. "Benchmarking in the Public Sector: A Critical Conceptual Framework." Public Administration 85(3):829-46.

Walters, William. 2004. "The Political Rationality of European Integration." In Global Governmentality: Governing International Spaces, edited by Wendy Larner, and William Walters, 155-73. London and New York: Routledge.

Wendt, Alexander. 1987. "The Agent-Structure Problem in International Relations Theory." International Organization 41(3):335-70.

Wiener, Antje. 2007a. "Contested Meanings of Norms: A Research Framework." Comparative European Politics 5:1-17.

Wiener, Antje. 2007b. "The Dual Quality of Norms and Governance Beyond the State: Sociological and Normative Approaches to 'Interaction'." Critical Review of International Social and Political Philosophy 10(1):47-69.

Wiener, Antje. 2008. "European Responses to International Terrorism: Diversity Awareness as a New Capability?" Journal of Common Market Studies 46(1):195-218.

Wiener, Antje. 2014. A Theory of Contestation. Berlin: Springer.

Zürn, Michael, and Jeffrey T. Checkel. 2005. Getting Socialized to Build Bridges: Constructivism and Rationalism, Europe and the Nation-State. International Organization 59:1045-79. 